\title{
Salvando a vida ou a si próprio: um comentário crítico ao fragmento 5 West, de Arquíloco
}

\author{
Luíza Monteiro de Castro Silva Dutra \\ Programa de Pós-Graduação em Letras: \\ Estudos Literários - FALE/UFMG \\ izamonteiro@yahoo.com.br
}

\begin{abstract}
This paper tries to enrich a philological discussion regarding Archilocus' fragment 5 West. Textual criticism tradition has been arguing whether psykhén or autón should be taken into account in the beginning of the fragment's third line. Since our aim is to decide which term is more appropriate, relevant modern commentaries related to the subject and some Homeric passages have been consulted in order to support our arguments.

KEYWORDS: Greek literature; Greek lyric poetry; Archilochus; fragments; textual criticism.

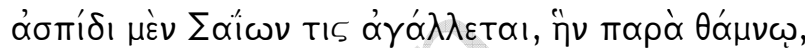

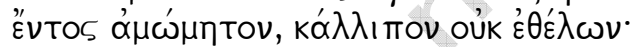

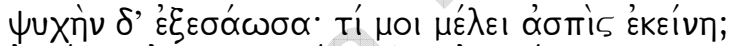

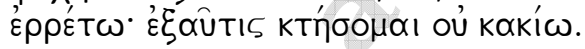

(Arquíloco fr. 5 West) ${ }^{1}$

C'um escudo ufana-se um saio, que nu'a moita, incensurável arma, invito fui depor.

Salvei a vida, que me importa aquele escudo?

Que se vá! Arranjo um não inferior. ${ }^{2}$

Os fragmentos da lírica de Arquíloco foram-nos transmitidos através de fontes de dois tipos: os papiros e inscrições epigráficas e as citações de autores antigos, que pela grande quantidade evidenciam a importância que teve sua poesia. Cada um desses grupos apresenta ao editor crítico (e ao comentador) problemas de ordens diferentes. Se nas fontes diretas há que se enfrentar extensas mutilações e problemas tipográficos, nas citações, por outro lado, o estabelecimento do texto é dificultado por tais fontes serem pouco confiáveis. Tal falta de crédito justifica-se com o hábito entre os antigos de citar uma passagem de outro autor (ou mesmo fazer uma referência intratextual) da forma como ela lhes vinha à cabeça, não envolvendo consulta prévia a qualquer manuscrito do

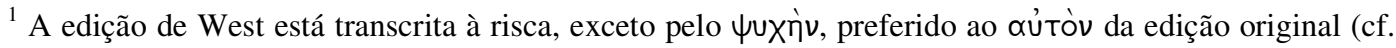
Delectus ex iambis et elegis Graecis. New York: Oxford University Press, 1980).

2 Tradução nossa.
} 
texto referido. E da memória imprecisa de alguns desses autores surgiram, assim, mudanças consideráveis com relação aos originais, muitas das quais foram repetidas por outros, que ao fazerem menção a uma certa passagem não se basearam na fonte primária, mas transcreveram uma já corrompida cita. Dessa forma, "toda uma série de citações pode ocorrer em dois ou três escritores diferentes, com as mesmas distorções". 3

Como marca West, erros são cometidos com freqüência durante o processo de citação. É muito fácil trocar palavras de lugar, trocar termos por sinônimos, ou mesmo misturar uma passagem a alguma outra similar. "Outra coisa com a qual se deve ter cuidado é que ele (o que cita) pode deliberadamente adaptar a construção ou algum outro aspecto da citação para atender a seus próprios propósitos”. 4

O fragmento 5 West de Arquíloco ${ }^{5}$ - sobre o qual pretendemos então tecer um breve comentário crítico - traz ainda uma outra dificuldade, posto que se trata de uma compilação de testemunhos de autores antigos, não aparecendo integralmente em nenhuma das fontes. ${ }^{6}$ São bastante diferentes as intenções dos autores ao citar ou referirse ao poema, o que se reflete em recortes múltiplos e na presença de muitas variantes. $\mathrm{O}$ terceiro verso, o mais problemático e o centro de nosso estudo, possui cinco variantes e

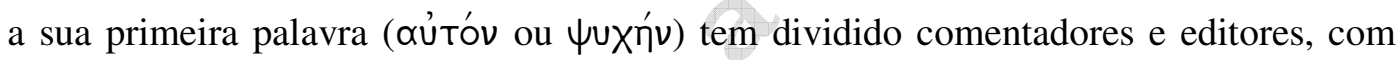
apresentação de argumentos de toda ordem. A própria discussão de um provável diálogo com a tradição da épica homérica tem fundamentado escolhas dos dois lados. ${ }^{7}$

Nesse caso, o estudo do contexto em que as citações ocorrem é essencial para se conjeturar a respeito das possíveis modificações intencionais por parte dos citantes. Há que se considerar também a época em que foram emitidos os testemunhos, os dialetos em que foram escritos, os gêneros a que pertencem as obras etc., a fim de analisar se houve alguma adaptação - consciente ou não - do texto original, tal como inversão sintática, uso de termos dublês e variação dialetal.

Para o editor crítico, principalmente, um fragmento como Arquil. fr. $5 \mathrm{~W}$ representa um grande desafio. É preciso determinar o que incluir no texto, levando em

\footnotetext{
${ }^{3}$ Cf. West, M. L. Textual criticism and editorial technique aplicable to Greek and Latin texts. Stuttgart: Teubner, 1973, p. 18.

${ }^{4}$ Cf. West, op. cit., p. 18.

${ }^{5} \mathrm{O}$ fragmento corresponde ao 6 Diehl, 6 Bergk, 13 Lassere-Bonnard e 12 Adrados.

${ }^{6}$ Há consenso de que não se trata de um fragmento de um poema maior, dado o equilíbrio e a coerência do todo [cf. Assunção, T. R. Comentários a Arquíloco 5, 14, 2 e 1 (W). Belo Horizonte: NAPQ-FALE/ UFMG, 1992, p. 15].

${ }^{7}$ Adkins [cf. Poetic craft in the early Greek elegists. Chicago/ London: The University of Chicago Press, 1985, p. 216 (nota 65)] e Assunção (cf. op. cit., p. 11-12) recorrem a exemplos da Ilíada na defesa de um ๔ủtóv; Di Benedetto (cf. Archil. Fr. 5 W. Eikasmós, v. 11, 1991, p. 21-27) traz leituras da Ilíada e da Odisséia em apoio à lição contrária. $\mathrm{O}$ debate será retomado mais adiante.
} 
conta que ainda que não haja como apresentar o fragmento cercado pelo contexto (por se tratarem de muitas fontes e nenhuma delas conter uma versão integral), todas as fontes devem ser incluídas na edição, assim como algo do contexto em que a citação ocorre, com vistas à orientação do leitor. O formato sugerido por $\mathrm{West}^{8}$ e aquele adotado também nas edições de Diehl, Lassere-Bonnard e Adrados, consiste na seleção de variantes e na montagem de um fragmento, impresso isoladamente. Quanto às fontes e contextos em que ocorrem as citações, são alojadas em algum lugar abaixo do texto (logo acima do aparato crítico). Isso acaba tornando ao leitor mais difícil a leitura dos fragmentos em seu contexto, mas parece ser a solução mais razoável para um tal caso.

\section{As citações e seus contextos}

Aristófanes é o primeiro a citar o fragmento, mas além do comediógrafo também preservaram versos do poema Plutarco, Sexto Empírico, Estrabão, o autor desconhecido de A vida de Arato e os neoplatônicos Proclo, Olimpiodoro, Elias e Pseudo-Elias. ${ }^{9}$ Outros autores como Crítias, Eustácio e Filóstrato não chegaram propriamente a citar, mas fizeram referências ao poema. ${ }^{10}$

\section{Aristófanes (A paz, v. 1298-99; 1301)}

No mais antigo dos testemunhos, nos versos 1298-1304 da peça $A$ paz de Aristófanes, o comediógrafo põe o primeiro, o segundo e parte do terceiro verso (até a cesura masculina) do poema de Arquíloco na boca de um menino que lhe serve de antítese a um outro garoto, filho de Lâmaco. Esse último havia anteriormente citado versos militarescos de forma redundante, dentre eles alguns iliádicos. A fala do segundo menino é interrompida por Trigeu no verso 1300, que lhe pergunta se canta para o pai. O menino não responde, apenas prossegue com um "salvei a alma/ vida" ( $\psi$ ư⿱宀 $v$ $\left.\delta ’ £ \xi \xi \sigma \alpha \alpha^{\prime} \omega \sigma \alpha\right)$, a que Trigeu replica no segundo hemistíquio: "para a vergonha dos

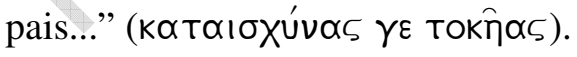

\footnotetext{
${ }^{8}$ Cf. West, op. cit., 1973, p. 96.

${ }^{9}$ Plutarco, Estrabão e o autor de A vida de Arato não citaram ou citaram de forma incompleta o terceiro verso e por isso não nos prolongaremos no exame de seus testemunhos.

10 Devemos ao minucioso estudo de Corrêa (cf. Homero e Arquíloco. Leituras modernas da Grécia Arcaica. In: _. Armas e varões. A guerra na lírica de Arquíloco. São Paulo: Editora da UNESP, 1998) informações fundamentais sobre os contextos em que se encontram as menções e citações a este poema de Arquíloco.
} 
A grande questão da versão aristofânica é a aparição de $\psi u \times \eta ́ v$, única da tradição. ${ }^{11}$ Todas as outras fontes apresentam aưtóv (com pequenas variações). É certo que o respeito à fonte mais antiga obviamente não é obrigatório e a antigüidade de um texto não pode servir como único critério na escolha de uma variante. Mas, da mesma forma, a quantidade de testemunhos por si só também não basta para justificar a opção por aưtóv. Como, então, definir a melhor opção?

$\mathrm{O}$ argumento dos que não aceitam o testemunho de Aristófanes como autêntico

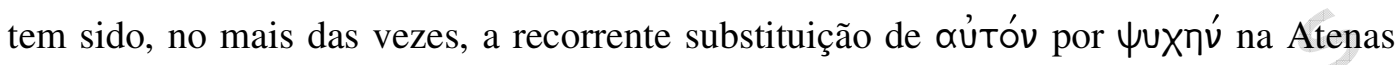
do quinto século. Para eles, pois, Aristófanes teria adequado ao grego ático o verso do poeta lírico. West julga tratar-se ou de uma "variante oral" de đưtóv - que não seria usado como pronome reflexivo àquela época - ou de uma "comum confusão de

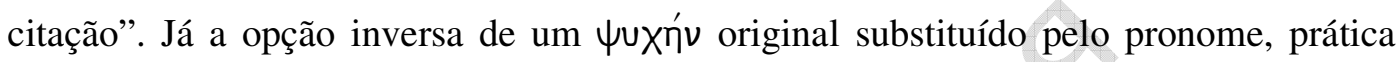
comum entre os neoplatônicos, é considerada improvável. ${ }^{12}$ Adkins, por sua vez, aponta uma interessante função para o reflexivo que, no início do verso, serviria de contrapeso

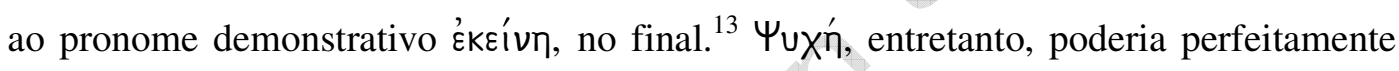
servir ao mesmo propósito, ainda que de forma menos marcada que um reflexivo de primeira pessoa, por exemplo. ${ }^{14}$

Por fim, recorrendo aos usos em Homero, a corrente dos defensores da lição

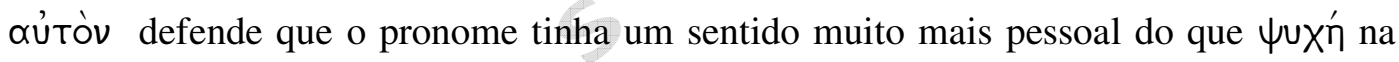
Grécia arcaica. O contraste entre os usos em $I l$. 1.3-4 é apontado como exemplo: ${ }^{15}$

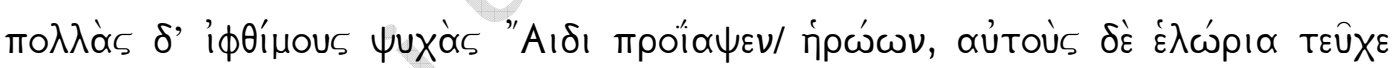

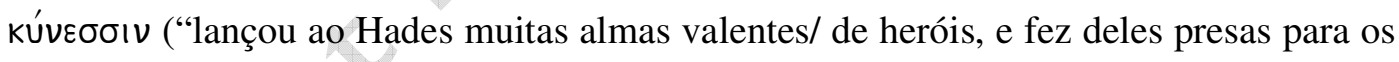
cães").

Contudo, é indiscutível que đủTóv era usado como reflexivo anafórico apenas na terceira pessoa e não se justifica a referência a uma primeira pessoa. Pensar que o “eu” do poema utiliza tal pronome para enfatizar sua posição apartada do escudo, em decorrência da fuga, ${ }^{16}$ não nos parece plausível. É antes uma conjectura levada ao extremo por comentadores em defesa de suas teses, não levando em conta a inexistência

\footnotetext{
${ }^{11}$ Dada a nossa preferência pela variante de Aristófanes, situamos aqui a maior parte da discussão sobre a contenda entre $\psi u x$ ñv e aútóv.

${ }_{12}$ Cf. West, M. L. Studies in Greek elegy and iambus. Berlin: De Gruyter, 1974, p. 118.

${ }^{13}$ Cf. Adkins, op. cit., p. 53.

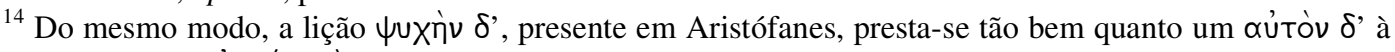

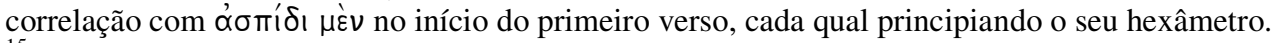

${ }^{15}$ Cf. Assunção, op. cit., p. 12.

${ }^{16}$ É essa a leitura de Adkins [cf. op. cit., p. 215 (nota 64)].
} 
de um uso semelhante do pronome em língua grega. Pois ainda que haja passagens em Homero em que aútóv é usado como reflexivo de primeira ou segunda pessoa, por Éuautóv (Il. 24.430; Il. 24.503; Il. 24.557s; Od. 14.388s), isso ocorre em contextos bastante específicos. Em todos esses versos homéricos mencionados, aưtóv é acompanhado da conjunção $\tau \varepsilon$, circunstância ausente no poema de Arquíloco. Mais além, os passos homéricos pressupõem uma interlocução que se vem enfatizar de forma muito forte, com a exclusão de um dado externo e a evidenciação de quem fala ou de quem escuta o discurso. ${ }^{17}$ Para que isso ocorra é necessária uma interlocução bem marcada, como em Il. 24.503, quando Príamo dirige-se ao ali presente Aquiles para

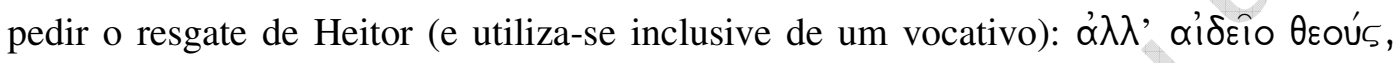

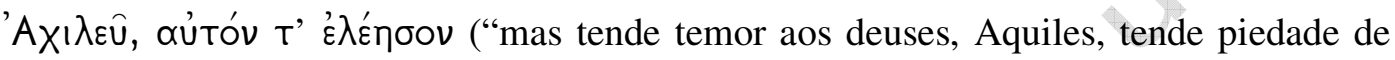
mim”). No fragmento de lírica em questão não se verifica nem mesmo a presença de um interlocutor a que se dirija um discurso direto.

No limite, a leitura de um aútòv $\mu^{\prime}$, conforme Proclo e Elias, poderia ser aceita, já que a referência à primeira pessoa é explicitada pelo pronome pessoal, funcionando como uma sorte de dêitico. Aliás, o uso de aưTóv e formas similares em conjunto com um pronome pessoal, com função reflexiva, também não é incomum em Homero (Il. 1.271; Il. 8.529). Em contrapartida, aútòv $\delta$ ', correção de Hoffmann ${ }^{18}$ e opção também de Diehl, Hudson-Williams e West, não parece caber. Falta um dado. "No contexto em

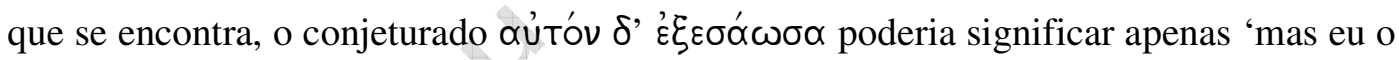
salvei', a ele, um dos saios", ${ }^{19}$ o que não faz lá muito sentido. E é refutável também a justificativa de West, explicitada nos comentários a passagens de Arquíloco: optou por $\delta^{\prime} \varepsilon$ para o contraste com $\mu \varepsilon^{\prime} \nu$ no primeiro verso. Mas a coordenação com $\mu \varepsilon^{\prime} \nu$ poderia simplesmente não ocorrer. ${ }^{20}$

E a variante de Aristófanes tem ainda outros argumentos a seu favor. Em primeiro lugar, as citações homéricas (v.1273-1276) feitas logo antes da citação a Arquíloco são fiéis, sem adaptações ou uso de termos dublês. Além disso, o uso de

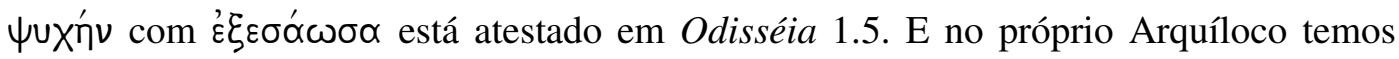
documentado um uso de $\psi \cup \times X^{\prime}$, no fragmento 213, sendo que neste caso "é o próprio

\footnotetext{
${ }^{17}$ Cf. Di Benedetto, V. Archil. Fr. 5 W. Eikasmós, Bolonha, v. 11, p. 23-25, 1991.

${ }^{18}$ Mas o próprio Hoffmann também admite aủiòv $\mu$ ' como leitura possível.

${ }^{19}$ Cf. Di Benedetto, op. cit., p. 25.

${ }^{20}$ Sobre o $\mu \varepsilon^{\prime} v$ solitarium e demais usos da partícula cf. Denniston, J. D. Greek particles. Oxford: 1954, p. 359-397.
} 


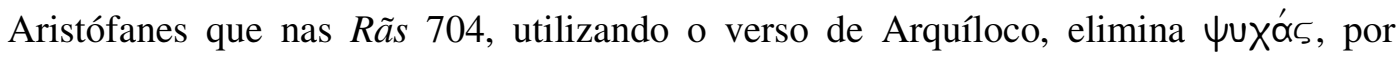
claras razões impostas pelo contexto". ${ }^{21}$

Pode-se dizer ainda que os dois termos causadores da controvérsia eram usados como dublês um do outro, especialmente após o período clássico. O que impediu em algumas situações o uso de um ou de outro foram as restrições que sofreram ao longo dos tempos, ou mesmo as imposições dos contextos. Mas se aútóv, por um lado, sofreu restrições de uso, $\psi \cup \times \dot{n}$, mais do que isso, sofreu fortes restrições de sentido, à medida que se foram formulando novas concepções de alma. Portanto, o choque entre a concepção de alma de Arquíloco e a dos que o citaram pode explicar perfeitamente a

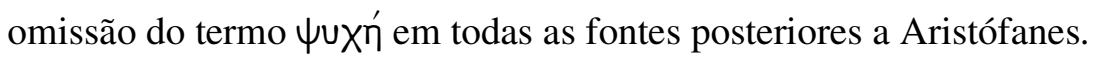

\section{Plutarco (Inst. Lac. 34)}

No relato de costumes dos lacedemônios (Instituta Laconica 34), Plutarco conta uma história duvidosa na qual Arquíloco teria sido expulso de Esparta por escrever num poema que seria melhor abandonar o escudo a perder a vida. Em meio a ela, cita os versos 1,2 e 4 inteiros, mas do terceiro omite o controverso princípio e só preserva os

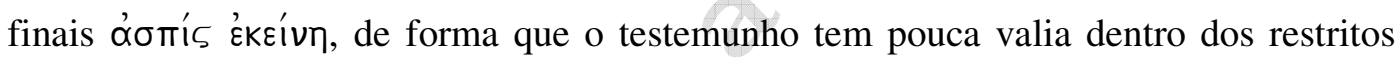
propósitos deste comentário.

\section{Sexto Empírico (Pyrrh. Hypot. 2.216)}

Quase cem anos mais tarde, em suas Hipotiposes Pirrônicas (3.216), Sexto Empírico cita os versos 1 e 2 integralmente. Apresenta também uma versão bem

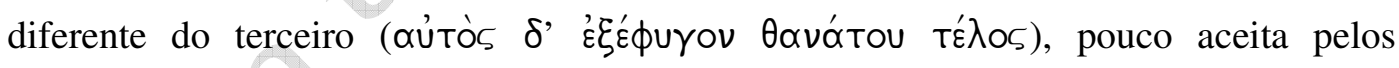
estudiosos não apenas por não ser corroborada por outros testemunhos, mas porque contém uma cesura evitada nas elegias e uma estranha "solenidade épica" inadequada àquele momento do poema. ${ }^{22}$

Conforme West, a variação é certamente fruto de uma falha de memória do

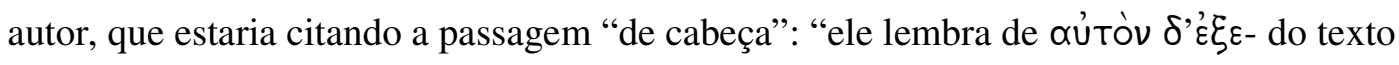

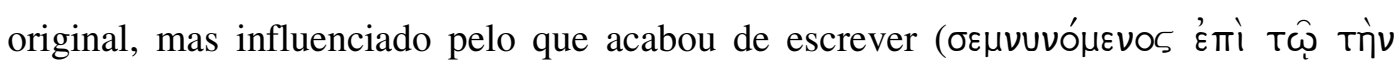

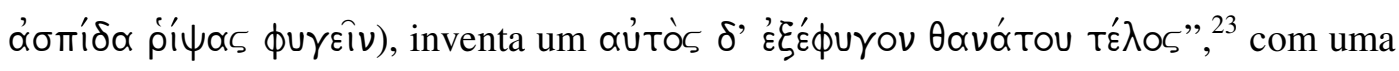
não de todo improvável reminiscência homérica. Também é possível que Sexto

\footnotetext{
${ }^{21}$ Cf. Di Benedetto, op. cit., p. 25.

${ }^{22}$ Cf. Adkins, op. cit., p. 216 (nota 65); Corrêa, op. cit., p. 114.

${ }^{23}$ Cf. West, op. cit., p. 118.
} 
Empírico tenha querido tornar o poema menos escandaloso e, de certo modo, livrar Arquíloco do julgamento moral feito pela tradição a que pertencem os testemunhos de Crítias e Plutarco.

Mas como bem lembra Assunção, ${ }^{24}$ ainda que seja infiel, a variante não é incompatível com uma leitura mais ampla do poema. É à morte que o "eu" do poema foge quando abandona seu escudo, abrindo, com isso, caminho para uma cadeia de possibilidades a que aquela botaria fim.

\section{Estrabão (10.2.17; 12.3.20) e o autor de $A$ vida de Arato (Vita Arati p. 77)}

Tanto na obra do geógrafo Estrabão quanto em A vida de Arato, as citações do poema de Arquíloco servem meramente como paradigmas para suas considerações acerca dos saios. Estrabão, que assistiu à passagem do primeiro século antes de Cristo, cita os dois primeiros versos do fragmento de Arquíloco em dois momentos de sua obra. Primeiro (10.2.17), ao associar o nome da ilha de Samos aos saios que teriam habitado a região. Depois (12.3.20), quando fala sobre os nomes próprios de alguns povos, assim como das mudanças de seus nomes. Já o autor de $A$ vida de Arato cita o dístico de Arquíloco para evidenciar a existência de duas cidades Saís, uma trácia e outra egípcia.

As variações com relação ao texto proposto por West são poucas. Na primeira

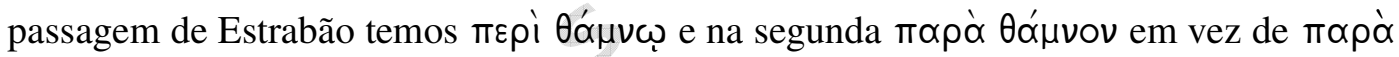
$\theta \alpha ́ \alpha \nu \omega$ (“junto a um matagal”). O mais plausível é que uma citação de memória tenha-o feito confundir as preposições.

\section{Os neoplatônicos (Proclo Pl. Alc. 1.139.26; Olimpiodoro Pl. Gorg. 140.28-144.2;} Elias Proleg. Philos. 8.20-22; Pseudo-Elias, Porf. Is 12.1-2)

Proclo, nos seus Comentários ao Alcibíades de Platão (1.139.26) cita apenas uma parte do segundo hexâmetro do poema, a qual é substantivada por um artigo no

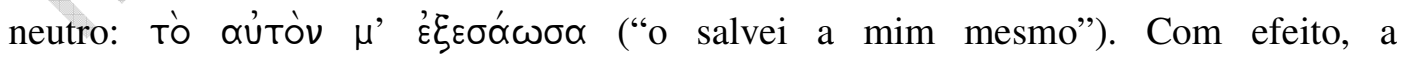
substantivação sugere que a expressão tenha se tornado uma espécie de lugar-comum à sua época. Mas não se pode precisar se por influência de Arquíloco ou não. Em Proclo, ela é utilizada para designar o amante que, vendo o amado mesquinho e voltado para as próprias coisas, volta-se ele também a si próprio. Nesse contexto, a lição đưTóv $\mu$ '

\footnotetext{
${ }^{24}$ Cf. Assunção, op. cit., p. 10-11.
} 
parece, de fato, mais conveniente do que $\psi u \times \Upsilon \dot{\eta} \nu \delta$, e serve como motivo satisfatório para justificar uma troca de termos da parte do filósofo.

Um outro neoplatônico, Olimpiodoro, já no séc. VI d.C. incluiu no seu comentário ao Górgias de Platão os versos 3 e 4 do fr. 5 W, sem fazer, no entanto, qualquer referência a Arquíloco. O contexto é a discussão de Cálicles sobre o que seria pior: ser injusto ou sofrer uma injustiça. $\mathrm{O}$ autor traça a clássica separação de corpo e alma, apontando que quando o corpo sofre injustiça não há grande mal, mas se a alma a

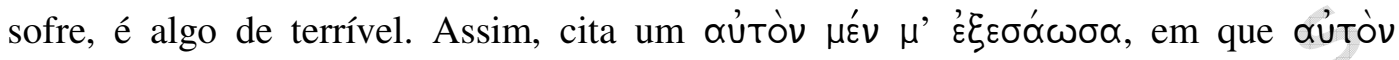
corresponderia à alma, enquanto o escudo do quarto verso, também citado, serviria de alegoria do corpo. Fica claro com o acréscimo de um $\mu \mathcal{k}^{\prime} \nu$ que se trata de uma adequação sintática do trecho. Não importaria a Olimpiodoro manter a provável contraposição original entre os dois primeiros versos e os dois últimos do poema (marcada pela coordenação $\mu \varepsilon^{\prime} \nu / \delta_{\varepsilon}^{\prime}$ ), mas interessava-lhe, antes, o novo sentido que criava com a apropriação dos dois últimos versos, impondo-lhes uma nova coordenação.

Elias, tradicionalmente considerado aluno de Olimpiodoro, também é testemunha do fragmento. Nos Prolegômenos (8.20-22), cita o terceiro verso e a primeira palavra do quarto. A variante do terceiro contém, como a de Proclo, aútòv $\mu$ '

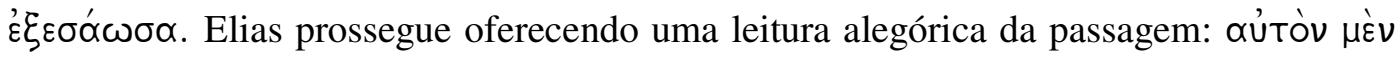

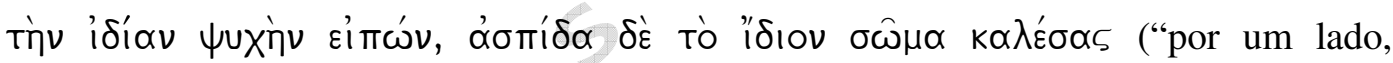
chamando sua alma de si próprio, por outro, seu corpo de escudo"). A mesma versão está contida nos Comentários à Isagoge de Porfírio (12.1-2), de Pseudo-Elias.

A opção por oưtóv em detrimento de $\psi u x$ ñ́v em todos os neoplatônicos que citaram o poema de Arquíloco justifica-se, certamente, pela preocupação com uma “renovação semântico-conceitual”. É bastante provável que eles tenham alterado o termo para que não se confundisse o conceito simples de $\psi \cup \times n ́$ no lírico citado com o conceito complexo que ora lhes havia conferido a filosofia neoplatônica. Como lembra Di Benedetto, no “comentário de Olimpiodoro ao Górgias de Platão a noção de 'salvar a alma' tem um valor ético incompatível com o uso em Arquíloco". ${ }^{25}$ Estendemos, aqui, seu apontamento a Proclo, Elias e Pseudo-Elias, que igualmente introduzem um trecho do poema para evocar um contexto inexistente em Arquíloco.

É problemático, de uma forma geral, fiar-se em citações de filósofos quando nas variantes está envolvido um termo de sentido fluido. Nos textos filosóficos da

\footnotetext{
${ }^{25}$ Cf. Di Benedetto, op. cit., p. 26.
} 
Antigüidade, termos correntes são comumente apropriados e a eles se lhes aplicam novos e precisos sentidos. E especialmente num caso como o de $\psi u \times \mathfrak{\eta}$, um termo de enorme variação conceitual, é mais do que natural realizarem-se adaptações terminológicas no processo de citação - a não ser quando o interesse é justamente preservar o termo para criticar ou questionar a posição do autor citado. Tendo isso em mente, a confiar na integridade da citação dos neoplatônicos preferimos ater-nos à de Aristófanes.

Na ausência de um forte impedimento à adoção da variante aristofânica, também não há por que fazer conjeturas, selecionando o que há de mais razoável em uma e outra fonte a fim de montar um poema pretensamente perfeito. As conjecturas de Hoffmann, Diehl, Hudson-Williams e West desembocam num aútòv $\delta$ ' que provém da concordância entre fontes (Sexto Empírico e Olimpiodoro; Aristófanes e os

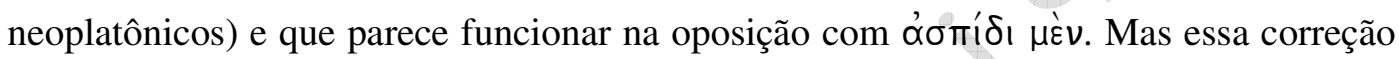
é desabonada pelo já mencionado fato de que aủiòv só se presta ao uso reflexivo em referência à terceira pessoa. O excesso de zelo pode, pois, conduzir à hipercorreção, erro não raro no trabalho de crítica textual, mas que se pode evitar com a observância de que a própria correção torna-se desnecessária quando se dispõe de um testemunho remoto, completo em sentido e gramaticalmente impecável como o de Aristófanes.

\section{Referências}

ADKINS, A. W. K. Poetic craft in the early greek elegists. Chicago/ London: The University of Chicago Press, 1985.

ADRADOS, F. R. Líricos griegos. Elegiacos y yambógrafos arcaicos (Siglos VII-V a. C.). Barcelona: Alma Mater, 1956. Vol. 1.

ARCHILOQUE. Fragments. Texte établi par François Lassere, traduit et commenté par André Bonnard. Paris: Les Belles Lettres, 1968.

ASSUNÇÃO, T. R. Comentários a Arquíloco 5, 14, 2 e 1 (W). Belo Horizonte: NAPQFALE/ UFMG, 1992.

CORRÊA, P. C. Homero e Arquíloco. Leituras modernas da Grécia Arcaica. In: . Armas e varões. A guerra na lírica de Arquíloco. São Paulo: UNESP, 1998.

CRESPO, E.; CONTI, L.; MAQUIERA, H. Sintaxis del griego clásico. Madrid: Gredos, 


\section{nuntius antiquus}

2003.

DI BENEDETTO, V. Archil. Fr. 5 W. Eikasmós, Bolonha, vol. 11, p.13-27, 1991.

DIEHL, E. Anthologia lyrica Graeca. Leipzig: Teubner, 1952.

HUDSON-WILLIAMS, T. Early greek elegy. Cardiff: University of Wales Press, 1926.

WEST, M. L. Delectus ex iambis et elegis Graecis. New York: Oxford University Press, 1980.

Textual criticism and editorial technique aplicable to Greek and Latin texts. Stuttgart: Teubner, 1973.

. Studies in Greek Elegy and Iambus. Berlin: De Gruyter, 1974. 